\title{
Effects of canagliflozin are mostly observed at first follow-up, within 6 months of commencement: results for the ABCD canagliflozin audit
}

\author{
THOMAS SJ CRABTREE, 1,2 PETER WINOCOUR, ${ }^{2}$ KEN DARZY, ${ }^{2}$ SUZANNE PHILLIPS, ${ }^{3}$ ALISON EVANS, ${ }^{3}$ \\ ANURITA ROHILLA, ${ }^{4}$ RAJEEV RAGHAVAN, ${ }^{5}$ DEVESH SENNIK, ${ }^{6}$ ALEX BICKERTON, ${ }^{7}$ ISKANDAR IDRIS, ${ }^{8}$ \\ MAHENDER YADAGIRI, ${ }^{9}$ ROBERT EJ RYDER, ${ }^{9}$ ABCD CANAGLIFLOZIN AUDIT CONTRIBUTORS
}

\begin{abstract}
Introduction: Canagliflozin was initially approved for use in the UK in March 2013. Randomised control trial evidence has demonstrated multiple beneficial effects. Many of these are present at initial follow-up and within 26 weeks of randomised control trial data. Our aim was to assess whether the beneficial effects of canagliflozin on multiple clinical and biochemical parameters occurred prior to first follow-up and, if so, whether these continued to improve or simply persisted at second follow-up.

Methods: Data were extracted from the $A B C D$ nationwide canagliflozin audit to include a minimum dataset of a baseline value and one (or two) follow-ups for each value.

Results: A total of 1,214 patient datasets were identified and used in the analysis: mean \pm SD age $60.1 \pm 10.6$ years; median duration of diabetes 8 (IQR 2.4-12.6 years); baseline $\mathrm{HbA}_{1 \mathrm{c}}$ $75.1 \pm 17.4 \mathrm{mmol} / \mathrm{mol}(9.0 \pm 1.59 \%)$ and weight $97.8 \pm 22.0 \mathrm{~kg}$. $68.3 \%$ of the patients were Caucasian where this was known ( $n=183$ ). At first follow-up (median 0.7 years) from baseline: change in $\mathrm{HbA}_{1 \mathrm{c}}-9.3 \mathrm{mmol} / \mathrm{mol}(95 \% \mathrm{Cl}-8.2$ to -10.4 ; $\mathrm{p}<0.0001)$, weight $-2.3 \mathrm{~kg}(95 \% \mathrm{Cl}-1.9$ to $-2.5 ; \mathrm{p}<0.0001)$;
\end{abstract}

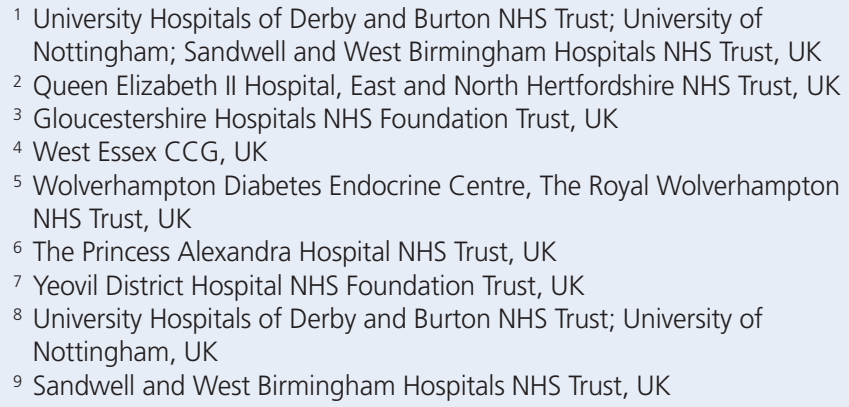

Address for correspondence: Dr Thomas SJ Crabtree Department of Diabetes, Royal Derby Hospital, Uttoxeter Road, Derby, DE22 3NE

E-mail: t.crabtree@nhs.net

https://doi.org/10.15277/bjd.2020.258
BMI $-0.7 \mathrm{~kg} / \mathrm{m}^{2}(95 \% \mathrm{Cl}-0.6$ to $-0.8 ; \mathrm{p}<0.0001) ;$ alanine aminotransferase $-2 \mathrm{U} / \mathrm{L}(95 \% \mathrm{Cl}-1.3$ to $-2.7 ; \mathrm{p}<0.0001)$; eGFR $-0.9 \mathrm{~mL} / \mathrm{min} / 1.73 \mathrm{~m}^{2}$ (95\% Cl -0.4 to $\left.-1.4 ; \mathrm{p}<0.001\right)$; systolic blood pressure (BP) $-2.6 \mathrm{mmHg}(95 \% \mathrm{Cl}-1.6$ to -3.5 ; $\mathrm{p}<0.0001)$ and diastolic $\mathrm{BP}-0.9 \mathrm{mmHg}(95 \% \mathrm{Cl}-0.2$ to -1.6 ; $p<0.001)$. Significant differences persisted comparing second follow-up (median 1.2 years) to baseline, but no further significant changes were noted between first follow-up and second follow-up other than in weight and BMI with further change in weight $-0.65 \mathrm{~kg}(95 \% \mathrm{Cl}-0.2$ to $-1.1 ; \mathrm{p}=0.047)$. Conclusion: The improvements following canagliflozin in this real-world cohort seem to occur within the first 0.7 years of treatment, which is similar to randomised controlled trial data. These improvements seem to be maintained over the next 6 months, with significant further weight loss occurring between 0.7 years and 1.2 years, although the mechanism of this is unclear and might be due to confounders. More evidence on this point is needed.

Br J Diabetes 2020;20:113-116

Key words: canagliflozin, real-world, observational, $\mathrm{HbA}_{1 \mathrm{c}}$, follow-up

\section{Introduction}

The Association of British Clinical Diabetologists (ABCD) canagliflozin audit was originally launched in January 2016 and was the second nationwide sodium-glucose linked transporter 2 inhibitor (SGLT2) audit to be launched in the UK following the launch of the dapagliflozin audit in 2015. Since the launch of the tool, over 100 anonymised clinical datasets have been collected allowing us to effectively assess the use of these medications in a real-world cohort. More recently, data have been provided by Clinical Commissioning Groups on their use of the drugs, allowing us to include larger numbers and produce more robust analyses as a result.

Canagliflozin was initially approved in the UK in March 2013. ${ }^{1}$ Randomised controlled trials including meta-analyses on its use have shown multiple beneficial effects including: 
- Reductions in $\mathrm{HbA}_{1 \mathrm{c}}$ and improvements in time-in-range ${ }^{2-8}$

- Improved cardiovascular and renal outcomes including blood pressure $^{9,10}$

- Possible improvements in liver function and reduction in alanine aminotransferase (ALT) ${ }^{11-15}$

- Reductions in triglyceride levels 8 ,14

Many of the studies were performed over different time frames with some phase III trials versus placebo conducted over 24 weeks and some extending up to 104 weeks in open-label extensions. Notably, many of the outcomes of these studies tend to be fairly similar despite longer exposure to the drugs, with the understandable exception of clinical cardiorenal endpoints. Forst et al demonstrated broadly similar outcomes with canagliflozin with either $100 \mathrm{mg}$ or $300 \mathrm{mg}$ added to metformin and/or pioglitazone at both 26 and 52 weeks with $\mathrm{HbA}_{1 \mathrm{c}}$ changes of $-0.89 \%$ and $-0.92 \%$, respectively. ${ }^{3}$ This is echoed in further clinical parameters, with changes from baseline at 26 weeks sustained at 52 weeks but with no further statistically significant improvements.

As further evidence, comparing just two different trials, a trial of 26 weeks duration adding canagliflozin, sitagliptin or placebo to metformin monotherapy showed $\mathrm{HbA}_{1 \mathrm{c}}$ reductions of $0.73 \%$ and weight reductions of $3.3 \mathrm{~kg} .{ }^{4}$ These are broadly similar to the results of one trial over 52 weeks which reported a $0.82 \%$ reduction in $\mathrm{HbA}_{1 \mathrm{c}}$ from baseline and weight reductions of $4.2 \mathrm{~kg} .{ }^{2}$ This particular study was subsequently extended to 104 weeks and $\mathrm{HbA}_{1 \mathrm{c}}$ reductions were maintained at $-0.65 \%$ from baseline.

\section{Methods}

Data were downloaded from the ABCD canagliflozin audit tools as well as anonymised data from five Clinical Commissioning Groups. All patients with a minimum dataset of a baseline value and one or two further values following commencement of canagliflozin were included in the analysis for each variable. Variables assessed included: $\mathrm{HbA}_{1 \mathrm{c}}(\mathrm{mmol} / \mathrm{mol}$ and \%), weight, body mass index (BMI), estimated glomerular filtration rate (eGFR), systolic and diastolic blood pressure (SBP and DBP), alanine aminotransferase levels (ALT), triglycerides and total cholesterol.

Changes in the above variables between baseline and first return to clinic and second return to clinic were analysed to determine whether further changes (eg, further $\mathrm{HbA}_{1 \mathrm{c}}$ reductions or weight loss) are achieved with prolonged use of canagliflozin or whether any benefit occurs over a more immediate period following commencement.

Data were screened for possible erroneous values. Those without the necessary follow-up data were also excluded. A flow chart showing the inclusion and exclusion of patient datasets is given in Figure 1.

\section{Statistical analysis}

All data were assessed for skewness. Data following a normal (parametric) distribution were analysed using paired t-tests. Data following a non-parametric distribution were analysed using Wilcoxon signed rank tests. Analyses were performed using Stata SE 16.
Figure 1. Flow chart showing the number of patient datasets entered into this observational analysis, their means of entry and the numbers excluded due to missing follow-up data

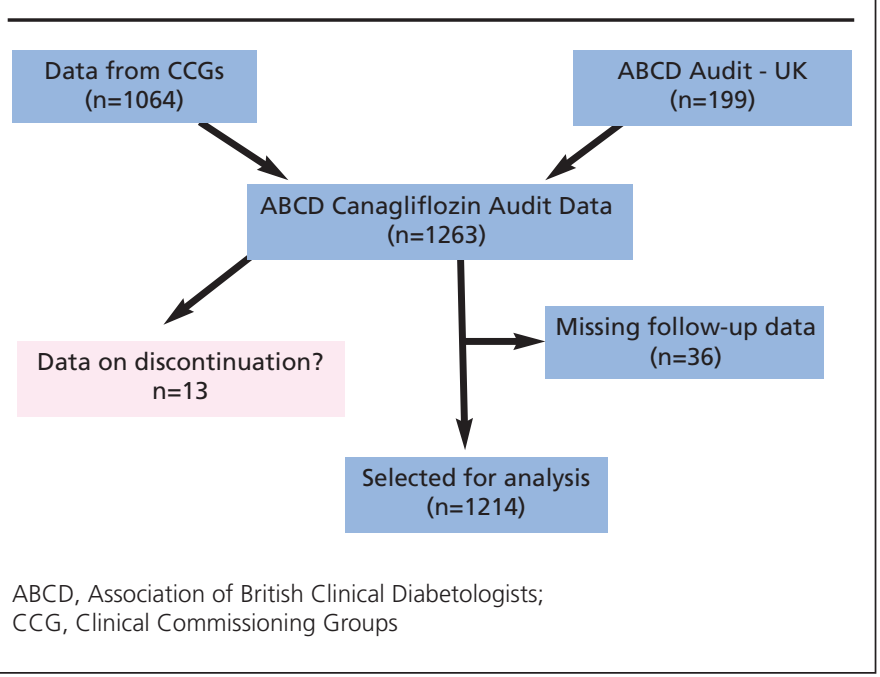

\section{Results}

A total of 1,214 individual patient datasets were identified for inclusion with the minimum required dataset of baseline plus one or two follow-up entries with data for at least one variable. The population had a mean \pm SD age of $60.1 \pm 10.6$ years; $60.8 \%$ were male. Due to missing data, ethnicity was available for just 186 of those included of which $68.3 \%(n=127)$ were classified as 'white British'. The mean \pm SD baseline $\mathrm{HbA}_{1 c}$ was $9.0 \pm 1.59 \%$ or $75.1 \pm 17.4 \mathrm{mmol} / \mathrm{mol}$. The mean weight at baseline was $97.8 \pm 22.0 \mathrm{~kg}$ with a BMI of $33.1 \pm 6.6 \mathrm{~kg} / \mathrm{m}^{2}$. The median duration of diabetes at baseline was 8 years (IQR 2.4-12.6). The remainder of the baseline characteristics of those included in the observed population are shown in Table 1.

Table 1 Baseline characteristics of observed population in this analysis of the $A B C D$ canagliflozin audit

\begin{tabular}{|c|c|}
\hline Characteristic & $n=1,214$ \\
\hline Mean \pm SD age, years & $60.1 \pm 10.6$ \\
\hline Male, \% & 60.9 \\
\hline Median (IQR) diabetes duration, years & $8(2.4-12.6)$ \\
\hline Caucasian, \% (where known, $\mathrm{n}=186$ ) & 68.3 \\
\hline \multicolumn{2}{|l|}{ Mean $\pm \mathrm{SD} \mathrm{HbA} A_{1 c}$} \\
\hline $\begin{array}{l}\% \\
\mathrm{mmol} / \mathrm{mol}\end{array}$ & $\begin{array}{l}9.0 \pm 1.59 \\
75.1 \pm 17.4\end{array}$ \\
\hline Mean \pm SD BMI, kg/m² & $33.1 \pm 6.6$ \\
\hline Mean \pm SD weight, $\mathrm{kg}$ & $97.8 \pm 22.0$ \\
\hline Median (IQR) ALT, U/L & $28.0(20-39)$ \\
\hline Mean \pm SD eGFR, mL/min/1.73 $\mathrm{m}^{2}$ & $79.2 \pm 16.0$ \\
\hline Mean \pm SD total cholesterol, $\mathrm{mmol} / \mathrm{L}$ & $4.3 \pm 1.1$ \\
\hline Mean \pm SD triglycerides, $\mathrm{mmol} / \mathrm{L}$ & $2.3 \pm 2.0$ \\
\hline
\end{tabular}

ALT, alanine aminotransferase; BMI, body mass index; eGFR, estimated glomerular filtration rate. 
Table 2 Baseline, 6-month and 12-month follow-up data for those included in the analysis of the ABCD canagliflozin audit

\begin{tabular}{|c|c|c|c|c|c|c|c|c|c|c|c|}
\hline & \multirow{3}{*}{$\begin{array}{l}\text { Baseline } \\
\text { Mean士SD* }\end{array}$} & \multicolumn{4}{|c|}{ Follow-up 1 (FU1) } & \multicolumn{6}{|c|}{ Follow-up 2 (FU2) } \\
\hline & & \multirow[t]{2}{*}{$\mathbf{n}$} & \multirow[t]{2}{*}{ Mean $\pm S D *$} & \multicolumn{2}{|l|}{$\begin{array}{l}\text { Mean difference from } \\
\text { baseline to FU1 }\end{array}$} & \multirow[t]{2}{*}{$\mathrm{n}$} & \multirow[t]{2}{*}{ Mean $\pm S D^{*}$} & \multicolumn{2}{|c|}{$\begin{array}{l}\text { Mean difference from } \\
\text { FU1 to FU2 }\end{array}$} & \multicolumn{2}{|l|}{$\begin{array}{l}\text { Mean difference from } \\
\text { baseline to FU2 }\end{array}$} \\
\hline & & & & Change $(95 \% \mathrm{Cl})$ & $P$ value & & & Change $(95 \% \mathrm{Cl})$ & $P$ value & Change $(95 \% \mathrm{Cl})$ & $P$ value \\
\hline $\mathrm{HbA}_{1 \mathrm{c}}(\%)$ & $9.0 \pm 1.59$ & 851 & $8.1 \pm 1.28$ & $-0.85(-0.75$ to -0.95$)$ & $<0.0001$ & 415 & $8.0 \pm 1.27$ & $-0.01(0.07$ to -0.1$)$ & 0.81 & $-0.75(-0.62$ to -0.88$)$ & $<0.0001$ \\
\hline $\mathrm{HbA}_{1 \mathrm{c}}(\mathrm{mmol} / \mathrm{mol})$ & $75.1 \pm 17.4$ & 851 & $65.0 \pm 14.0$ & $-9.3(-8.2$ to -10.4$)$ & $<0.0001$ & 415 & $64.4 \pm 13.9$ & $-0.1(0.8$ to -1.1$)$ & 0.81 & $-8.2(-6.8$ to -9.6$)$ & $<0.0001$ \\
\hline Weight (kg) & $97.8 \pm 22.0$ & 882 & $95.6 \pm 21.6$ & $-2.3(-1.9$ to -2.5$)$ & $<0.0001$ & 344 & $96.6 \pm 20.9$ & $-0.65(-0.2$ to -1.1$)$ & 0.047 & $-2.8(-2.1$ to -3.4$)$ & $<0.0001$ \\
\hline BMI $\left(\mathrm{kg} / \mathrm{m}^{2}\right)$ & $33.1 \pm 6.6$ & 882 & $32.2 \pm 6.8$ & $-0.7(-0.6$ to -0.8$)$ & $<0.0001$ & 344 & $32.3 \pm 6.6$ & $-0.2(-0.03$ to -0.3$)$ & 0.016 & $-0.9(-0.7$ to -1.1$)$ & $<0.0001$ \\
\hline $\operatorname{ALT}(\mathrm{U} / \mathrm{L})^{\dagger}$ & $28(20-39)$ & 721 & $25(19-35)$ & $-2(-1.3$ to -2.7$)$ & $<0.0001$ & 338 & $25(19-35)$ & $-1(-0.2$ to -1.8$)$ & 0.08 & $-3(-1.8$ to -4.2$)$ & $<0.0001$ \\
\hline eGFR (mL/min/1.73 m²) & $79.2 \pm 16.0$ & 801 & $76.5 \pm 14.5$ & $-0.9(-0.4$ to -1.4$)$ & 0.0005 & 352 & $76.4 \pm 13.6$ & $0.4(1.0$ to -0.2$)$ & 0.175 & $-0.5(0.18$ to -1.2$)$ & 0.148 \\
\hline Total cholesterol (mmol/L) & $4.3 \pm 1.1$ & 679 & $4.3 \pm 1.2$ & $0.0(0.06$ to -0.06$)$ & 0.98 & 230 & $4.3 \pm 1.2$ & $-0.1(0.04$ to -0.2$)$ & 0.197 & $0.0(0.1$ to -0.1$)$ & 0.972 \\
\hline Triglycerides (mmol/L) & $2.3 \pm 2.0$ & 297 & $1.6 \pm 1.3$ & $-0.6(-0.4$ to -0.8$)$ & $<0.0001$ & 230 & $0.9 \pm 2.3$ & $0.1(0.4$ to -0.2$)$ & 0.39 & $-0.4(0.1$ to -1.0$)$ & 0.143 \\
\hline Systolic BP (mmHg) & $132.6 \pm 15.4$ & 884 & $130.1 \pm 14.5$ & $-2.6(-1.6$ to -3.5$)$ & $<0.0001$ & 420 & $126.6 \pm 12.9$ & $-0.4(1.1$ to -1.8$)$ & 0.64 & $-2.4(-0.9$ to -3.8$)$ & 0.001 \\
\hline Diastolic BP (mmHg) & $77.8 \pm 10.0$ & 884 & $76.8 \pm 10.2$ & $-0.9(-0.2$ to -1.6$)$ & 0.007 & 420 & $75.7 \pm 9.7$ & $-0.8(0.1$ to -1.8$)$ & 0.09 & $-1.3(-0.4$ to -2.3$)$ & 0.008 \\
\hline
\end{tabular}

Baseline characteristics of those discontinuing canagliflozin $(n=13)$ were broadly similar to the included population. Unfortunately, due to the nature of the data, reasons and numbers of those who discontinued treatment were not available.

Median time between baseline and first follow-up was 0.7 years (IQR 0.5-0.9 years) and to second follow-up was 1.2 years (IQR 1-1.4 years). The results from the first and second followups including the numbers of patients in each analysis, mean difference, confidence intervals and statistical significance (derived from paired t-test or Wilcoxon signed rank test dependent on skewness) for all parameters are shown in Table 2. ALT levels were analysed by non-parametric methods due to a skewness of 2.35 indicating a non-normal distribution. No other parameters demonstrated significant skew to warrant non-parametric analysis.

The results demonstrate significant decreases in $\mathrm{HbA}_{1 \mathrm{c}}$, weight, BMI, ALT, SBP and DBP at first follow-up, with these changes persisting at second follow-up. However, no further statistically significant changes were observed between the first and second follow-ups in any parameter other than weight and BMI. Of note, a significant reduction in triglycerides was noted at first follow-up but not at second follow-up.

\section{Discussion}

These data demonstrated significant improvements in multiple parameters at the first follow-up visit, after approximately 0.7 years, which persisted but did not continue to improve at second follow-up for the majority except weight and BMI. A significant effect in reducing triglycerides was noted in this analysis, which has not been noted previously, although this effect was no longer present at 1 year.

Our results are comparable to randomised controlled trial data which showed that initial changes in $\mathrm{HbA}_{1 \mathrm{c}}$ persisted but clinically significant further decreases were not observed. ${ }^{2-4} \mathrm{Com}-$ paring our data with that included in the meta-analysis of randomised controlled trials by Xiong et al at approximately
26 weeks, $^{8}$ our cohort showed similar reductions in weight of $-2.3 \mathrm{~kg}$ versus $-2.23 \mathrm{~kg}$ in the meta-analysis and $\mathrm{HbA}_{1 \mathrm{c}}$ (only reported by Xiong et al as \%, $-0.85 \%$ vs $-0.7 \%$ in the metaanalysis). Reductions in SBP were greater in the meta-analysis $(-4.26 \mathrm{mmHg})$ than in our real-world cohort of patients $(-2.6$ $\mathrm{mmHg}$ ). Baseline characteristics of those included were not commented on in the meta-analysis so it is difficult to compare with the characteristics of our patients, although it seems likely that real-world usage will include many patients who would have been excluded from participation in one or more of the randomised controlled trials included in the meta-analysis.

It should be highlighted that the main limitations are the inability to adjust for some confounding factors such as concomitant medications or other comorbidity as these data were not captured within the scope of this observational audit of routine clinical data. It may therefore be that some of the results are affected by confounding factors, but we are reassured by the relative similarity of our results to already published randomised controlled trial data.

Interestingly, continuing improvements in weight and BMI were noted. This may be due to ongoing glycosuria and thus calorie loss but, as data on the presence of glycosuria were not collected, this is difficult to comment on directly. It may be that there is an alternative explanation or confounder such as a concomitant increase in exercise or change in diet which is difficult to appreciate using an observational dataset.

Our data are more likely to be generalisable to a UK population with diabetes and will include people with a mixture of comorbidity, extremes of weight and $\mathrm{HbA}_{1 \mathrm{c}}$ and other factors which would not have been included in randomised controlled trials.

\section{Conclusions}

Our analysis of this real-world observational dataset closely mirrors the results from many of the recent randomised controlled trials on canagliflozin use. This is encouraging evidence that the 


\section{Key messages}

- Canagliflozin use is associated with improvements in multiple clinically important parameters such as $\mathrm{HbA}_{1 \mathrm{c}}$ and weight in the real world, with results mirroring those of randomised controlled trials

- The most significant changes appear to occur shortly after commencement at approximately 6 months and are sustained at 12 months, although no further improvements are observed in most parameters

- Weight does continue to reduce after 6 months, which might be due to ongoing glycosuria and thus calorie loss in urine; more research on this point is needed

outcomes reported in such trials will translate well into a UKbased diabetes cohort. Most of the improvements in the variables we assessed seemed to occur over a relatively short period following commencement, but did not continue to improve significantly further after this other than for weight (and BMI). More real-world analyses are planned and should try to include analysis of adverse events or reasons for discontinuation and may focus on aspects such as ALT reductions, non-alcoholic fatty liver disease outcomes or impact on lipid profiles.

Conflict of interest TSJC reports grants and personal fees from NovoNordisk, grants from Sanofi, outside the submitted work. REJR has received speaker fees, and/or consultancy fees and/or educational sponsorships from AstraZeneca, BioQuest, GI Dynamics, Janssen and Novo Nordisk. RR reports: I have received consultation and/or lecture fees or unrestricted travel grants from Novo Nordisk, Eli Lilly, Boehringer Ingelheim, AstraZeneca, Takeda, Napp, Abbott Diabetes. I have had no inducements or direct sponsorship in relation to this study. PW reports personal fees from Advisory Board work with Napp, outside the submitted work. DS reports personal fees from Boehringer Ingelheim, personal fees from Sanofi, personal fees from Novo Nordisk, personal fees from AstraZeneca, personal fees from Merck, personal fees from Eli Lilly, outside the submitted work. MY, SP, AB, $A E, K D, A R$ have nothing to disclose.

Funding The $A B C D$ canagliflozin audit programme is funded by an unrestricted grant from Napp Pharmaceuticals.

Acknowledgement: The authors would like to thank the audit contributors (see Appendix 1 at www.bjd-abcd.com)

\section{References}

1. Johnson \& Johnson. U.S. FDA approves INVOKANA ${ }^{\text {TM }}$ (Canagliflozin) for the treatment of adults with type 2 diabetes. 2013. Available from: https://www.jnj.com/media-center/press-releases/us-fda-approves-invokana-canagliflozin-for-the-treatment-of-adults-with-type-2-diabetes (accessed 13 Jan 2020)

2. Cefalu WT, Leiter LA, Yoon K-H, et al. Efficacy and safety of canagliflozin versus glimepiride in patients with type 2 diabetes inadequately controlled with metformin (CANTATA-SU): 52 week results from a randomised, double-blind, phase 3 non-inferiority trial. Lancet 2013;382(9896):941-50. https://doi.org/10.1016/S0140-6736(13)60683-2

3. Forst T, Guthrie R, Goldenberg R, et al. Efficacy and safety of canagliflozin over 52 weeks in patients with type 2 diabetes on background metformin and pioglitazone. Diabetes Obes Metab 2014;16(5):467-77. https://doi.org/ 10.1111/dom. 12273

4. Lavalle-Gonzalez FJ, Januszewicz A, Davidson J, et al. Efficacy and safety of canagliflozin compared with placebo and sitagliptin in patients with type 2 diabetes on background metformin monotherapy: a randomised trial. Diabetologia 2013;56(12):2582-92. https://doi.org/10.1007/s00125-0133039-1

5. Rodbard HW, Peters AL, Slee A, et al. The effect of canagliflozin, a sodium glucose cotransporter 2 inhibitor, on glycemic end points assessed by continuous glucose monitoring and patient-reported outcomes among people with type 1 diabetes. Diabetes Care 2017;40(2):171-80. https://doi.org/ 10.2337/dc16-1353

6. Stenlof K, Cefalu WT, Kim K-A, et al. Long-term efficacy and safety of canagliflozin monotherapy in patients with type 2 diabetes inadequately controlled with diet and exercise: findings from the 52-week CANTATA-M study. Curr Med Res Opin 2014;30(2):163-75. https://doi.org/10.1185/ 03007995.2013 .850066

7. Wilding JP, Charpentier G, Hollander P, et al. Efficacy and safety of canagliflozin in patients with type 2 diabetes mellitus inadequately controlled with metformin and sulphonylurea: a randomised trial. Int J Clin Pract 2013;67(12):1267-82. https://doi.org/10.1111/ijcp.12322

8. Xiong W, Xiao MY, Zhang M, Chang F. Efficacy and safety of canagliflozin in patients with type 2 diabetes: a meta-analysis of randomized controlled trials. Medicine (Baltimore) 2016;95(48):e5473. https://doi.org/10.1097/ MD.0000000000005473

9. Perkovic V, Jardine MJ, Neal B, et al. Canagliflozin and renal outcomes in type 2 diabetes and nephropathy. N Engl J Med 2019;380(24):2295-306. https://doi.org/10.1056/NEJMoa1811744

10. Perkovic V, de Zeeuw D, Mahaffey KW, et al. Canagliflozin and renal outcomes in type 2 diabetes: results from the CANVAS program randomised clinical trials. Lancet Diabetes Endocrinol 2018;6(9):691-704. https://doi.org/10.1016/S2213-8587(18)30141-4

11. Cusi K, Bril F, Barb D, et al. Effect of canagliflozin treatment on hepatic triglyceride content and glucose metabolism in patients with type 2 diabetes. Diabetes Obes Metab 2019;21(4):812-21. https://doi.org/10.1111/ dom. 13584

12. Gautam A, Agrawal PK, Doneria J, Nigam A. Effects of canagliflozin on abnormal liver function tests in patients of type 2 diabetes with non-alcoholic fatty liver disease. J Assoc Physicians India 2018;66(8):62-6.

13. Bajaj HS, Brown RE, Bhullar L, Sohi N, Kalra S, Aronson R. SGLT2 inhibitors and incretin agents: associations with alanine aminotransferase activity in type 2 diabetes. Diabetes Metab 2018;44(6):493-9. https://doi.org/ 10.1016/j.diabet.2018.08.001

14. Itani T, Ishihara T. Efficacy of canagliflozin against nonalcoholic fatty liver disease: a prospective cohort study. Obes Sci Pract 2018;4(5):477-82. https://doi.org/10.1002/osp4.294

15. Leiter LA, Forst T, Polidori D, Balis DA, Xie J, Sha S. Effect of canagliflozin on liver function tests in patients with type 2 diabetes. Diabetes Metab 2016;42(1):25-32. https://doi.org/10.1016/j.diabet.2015.10.003 
Appendix 1. ABCD nationwide and worldwide canagliflozin audit contributors The following are those whom we know about

$A B C D$ nationwide canagliflozin audit - initial setup, maintenance and nationwide analysis:

Ryder REJ, Crabtree TJ, Puttanna A, Yadagiri M, Cull ML, Wyres M, Statistician: Blann A

\section{England}

Doncaster And Bassetlaw Hospitals NHS Foundation Trust (Bassetlaw Hospital): Chaturvedi P, Haq MUL, Sharif M. Doncaster And Bassetlaw Hospitals NHS Foundation Trust (Doncaster Royal Infirmary): Muniyappa S, Tekleberhan RF. East And North Hertfordshire NHS Trust (Queen Elizabeth I I Hospital): Darzy K, Idowu OA, Jayashekara A, Nickson R, Qureshi S, Winocour P, Zeeshan Y. Cheltenham General Hospital (Cheltenham): Evans A, Phillips S. NHS Birmingham CrossCity CCG (Lordswood House Group Medical Practice): Daniels T. NHS Coventry and Rugby CCG (Hillfields Health Centre - 1): Sani-Gusau G. NHS Dudley CCG (Feldon Lane Practice): Fox J, Thorns R. NHS Surrey Downs CCG (Ashley Centre Surgery): Hickery C. NHS Sutton CCG (Shotfield Medical Practice): Munden J. Princess Alexandra Hospital (Harlow): Sennik D. Royal Berkshire Hospitals NHS Trust (Berkshire): Gallen IW. Royal United Hospital Bath NHS Trust (Royal United Hospital Bath NHS Trust): Robinson T. Sandwell And West Birmingham Hospitals NHS Trust (City Hospital Birmingham): Crabtree TJ, Cull ML, De P, Guerero D, Kumar P, Puttana A, Ryder REJ, Wyres M, Yadagiri M. Sandwell And West Birmingham Hospitals NHS Trust (Dr Akhtar R): Akhtar R, Wyres M. Sandwell And West Birmingham Hospitals NHS Trust (Norvic Family Practice): Pathan H, Wyres M. Sandwell And West Birmingham Hospitals NHS Trust (Dr Pal P \& Partner): Jemahl S, Wyres M. University Hospitals Coventry And Warwickshire NHS Trust (University Hospital (Coventry)): Dimitriadis GK, Mytilinaiou M, Randeva HS. University Hospitals Of Leicester NHS Trust (Leicester General Hospital): Gallagher A, Gohil S. Yeovil District Hospital NHS Trust (Yeovil): Bickerton A.

\section{Scotland}

Dr CP Macfarlane \& Partner: Smith L. Largs Medical Group: Greenfield M.

\section{Wales}

Abertawe Bro Morgannwg University NHS Trust: Chowdhury SR, Cozma L, Kumar P. The Avicenna Medical Practice: Hussain R. YSBYTY GWYNEDD: Murtaza MO

Eclipse Users

Cheltenham General Hospital, Cheltenham, UK: Evans A, Phillips S. Pennine Acute Hospitals NHS Trust, Manchester, UK: Rowles S. Princess Alexandra Hospital, Harlow, UK: Sennik D. Royal Berkshire NHS Foundation Trust, UK: Gallen I. West Essex CCG, Essex, UK: Rohilla A. Yeovil District Hospital NHS Trust, Somerset, UK: Bickerton A.

\section{Acknowledgment}

The ABCD nationwide canagliflozin audit is an independent audit supported by an unrestricted grant from Janssen 